\title{
Beneath the surface: The influence of music and the dark triad traits on stress and performance
}

\author{
Teresa Gomes Arrulo $^{1}$ (D) $\cdot$ Michail Doumas $^{1}$ (D) $\cdot$ Kostas A. Papageorgiou $^{1}$ (D)
}

Accepted: 19 March 2021 / Published online: 29 March 2021

(C) The Author(s) 2021

\begin{abstract}
Examining factors that protect against the negative repercussions of stress on everyday functioning is paramount. This experimental study investigated the effects of music listening and personality on the reduction of perceived stress and cognitive performance. Seventy adults $(18-45$ years, $M=22.8, S D=6.6)$ completed measures of the Dark Triad traits (psychopathy, narcissism, and Machiavellianism), music preferences, and music uses, and undertook a stress-inducing procedure. Participants were randomly allocated to three groups: hip-hop/rap, classical music, control, being exposed to the respective genre or silence for $20 \mathrm{~min}$ after the predicted peak in stress. Results showed that classical and hip-hop/rap music equally facilitated stress reduction. Narcissism predicted lower stress when classical music preference was high. Narcissism also predicted enhanced performance but also greater stress, when paired with infrequent stress-management through music. These novel findings demonstrate how particular genres and traits, despite being predominantly negatively perceived, can enhance stress reduction or cognitive performance.
\end{abstract}

Keywords Music listening $\cdot$ Subclinical narcissism $\cdot$ Laboratory-induced stress $\cdot$ Performance $\cdot$ Music preferences $\cdot$ Music uses

Stress is an unavoidable response inherent to the human experience (Fink, 2010). Given its potentially damaging impact (Fink, 2010), identifying accessible stress-coping strategies is vital to preserve well-being and everyday performance under stress.

Music listening has been evidenced to improve stress responses (Moradipanah et al., 2009; Yehuda, 2011), being commonly employed as a stress-reducing strategy (Kemper \& Danhauer, 2005). Accordingly, multiple genres have been investigated in relation to stress (Finn \& Fancourt, 2018; Nilsson, 2008). However, genre discrepancies have been identified in music and stress literature, with classical music being favored over most genres (Finn \& Fancourt, 2018), especially hip-hop/rap, a genre commonly associated with undesirable behaviors (Gomes Arrulo, n.d.-a; Lozon \& Bensimon, 2014). Consequently, abundant evidence substantiates the stressreducing effects of classical music, and researchers typically label it "relaxing music" (Chafin et al., 2004; Elliott et al.,

Teresa Gomes Arrulo tgomesarrulo01@qub.ac.uk

1 School of Psychology, Queen's University Belfast, David Keir Building, 18-30 Malone Road, Belfast BT9 5BN, UK
2011). Contrastingly, despite its links to advantageous outcomes in therapeutic (Kirkland \& King, 2019) and schoolbased settings (Uhlig et al., 2018), and its features resembling those deemed 'relaxing' in literature (e.g. repetitive, rhythmic) (Elliott et al., 2011; Uhlig et al., 2018), research assessing the effect of hip-hop/rap listening on induced stress is scant.

Personality has also been evidenced to protect against the adverse effects of stress (Papageorgiou et al., 2019a). The Dark Triad (DT), a cluster of subclinical personality traits, consists of: psychopathy, characterized by high impulsivity, low empathy, and thrill-seeking behaviors; narcissism, characterized by a sense of entitlement, superiority, and selfconceit; and Machiavellianism, defined by deception and manipulation (Jones \& Figueredo, 2013; Paulhus \& Williams, 2002). Although known as socially aversive, evidence has linked the DT to successful behavioral outcomes (Jonason et al., 2020; Papageorgiou et al., 2017). Similarly to hip-hop/ rap, though, the association between the DT and stress remains unclear.

Psychopathy has been found to predict self-reported stress both favorably (Kajonius \& Björkman, 2018; McInerney, 2018) and adversely (Noser et al., 2014; Wendt \& Bartoli, 2019), with different psychopathy dimensions being potentially more advantageous than others (Wendt \& Bartoli, 2019). Narcissism has been linked to stress-reactivity, though the 
direction of this link may also depend on the dimension of narcissism explored (Coleman et al., 2019). Grandiose narcissism, defined by inflated self-assurance, has been evidenced to predict better stress-coping approaches than vulnerable narcissism, characterized by emotional fragility and need for social approval (Coleman et al., 2019; Zeigler-Hill et al., 2008), when stress was measured via self-report (Kajonius \& Björkman, 2018). Nonetheless, both dimensions, when alongside certain stressors and stress-reactivity indicators, may elicit maladaptive responses (Coleman et al., 2019). Machiavellianism, although predicted to minimize stress-reactivity, has been predominantly found not to be associated with self-reported stress (Kajonius \& Björkman, 2018; Noser et al., 2014). Previous literature on the associations between the DT traits and physiological stress (e.g. salivary cortisol, skin conductance) has also yielded mixed findings (Gomes Arrulo, n.d.-b).

Literature has also linked the DT to performance. Some findings suggest primary and secondary psychopathy are associated with deficits in attentional capacity and cognitive control, respectively (Sadeh \& Verona, 2008). Other studies, however, report no direct associations between psychopathy and cognition (Hare, 1984; Hart et al., 1990). Evidence suggests adverse scenarios and selfenhancement opportunities improve narcissists' performance by stimulating hostile goal pursuit and flexible use of behavioral strategies as a compensatory response (Hart et al., 2017; Papageorgiou et al., 2018; Wallace \& Baumeister, 2002). Machiavellianism has been associated with well-developed cognitive flexibility and inhibition (Fatima \& Shahid, 2020). Regarding performance under stress, specifically, a stress-inducing experiment found no associations between the DT and cognitive performance (McInerney, 2018). It is noteworthy that performance under stress is also modulated by one's stress-coping ability (Lin et al., 2017). As the DT traits may simultaneously influence stress-coping ability and performance, their association with these variables should be explored concurrently.

The influence of music and personality on stress and performance may vary when studied alongside other factors. For instance, narcissism has been evidenced to indirectly predict lower stress (Papageorgiou et al., 2019a) and reduce psychiatric symptoms, fostering adaptive tendencies that protect against psychopathology, through mental toughness (Papageorgiou et al., 2019b). Two factors that may influence both the efficacy of music listening interventions and the predictive value of personality traits regarding stress-related outcomes are music preferences and habitual music uses.

Literature indicates music preferences influence musicelicited stress reduction (Jiang et al., 2013; Jiang et al., 2016), potentially overriding the impact of stimuli features (Yehuda, 2011). Moreover, albeit research typically focuses on the influence of personality on music preferences, the latter can influence behaviors which degree of manifestation is partially determined by personality (Greenberg et al., 2015; Halko \& Kaustia, 2015). Therefore, as traits, music preferences may also predict stress responses. Furthermore, using music for emotion regulation is evidenced to augment the practice of cognitive reappraisal, an emotion regulation strategy involving the reframing of emotionally charged events (Chin \& Rickard, 2014; Saarikallio, 2008). By affecting stress-regulation ability, habitual music uses may alter the stress-reducing effects of music and, similarly to personality (Chamorro-Premuzic et al., 2009), impact one's proneness to use music for stress regulation. Hence, examining music preferences and uses is fundamental to capture the effects of music and personality on stress and performance.

\section{Present Study}

This study assessed the impact of hip-hop/rap and classical music on induced stress and examined whether stress levels and cognitive performance were predicted by DT trait scores. The moderating effects of music preferences and uses on these relationships were also investigated. This is the first study to assess the potentially advantageous influence of predominantly aversive variables (hip-hop/ rap, DT), whilst accounting for music preferences and uses, on stress and performance.

It was hypothesized that exposure to hip-hop/rap, given its relaxing potential, would generate significantly lower stress compared to silence, and that classical music would elicit the lowest stress levels across conditions during and after music/ silence exposure. High psychopathy and high narcissism scorers were hypothesized to display different stress levels and cognitive performance, compared to low psychopathy and narcissism scorers, respectively. Music preferences and uses were hypothesized to moderate the relationships between music and stress, personality and stress, and personality and performance.

\section{Methods}

\section{Pilot Study}

A pilot study with a total of 16 university students $(M=$ $23.8, S D=3.7 ; 75 \%$ females) was conducted to evaluate the feasibility of the procedure, the suitability of the arithmetic task difficulty, and the effectiveness of the stress manipulation (see Pilot Study Analysis in Online Resource 1). 


\section{Participants}

An a priori power analysis was conducted using G*Power 3 (Faul et al., 2007). Outcomes indicated that a sample of 69 participants would be required to achieve a power of $.9, f(U)=$ $0.50, \alpha=.05$. The $f(U)$ value was determined using the effect size derived from the pilot study analysis concerning the effect of music condition on stress.

Data were collected from seventy-six adults, although six were excluded from the analyses due to technical issues and missing data. The predicted target sample size was increased by one participant to account for any potential further issues. Participants' age ranged from 18 to 45 years $(M=22.8, S D=6.6 ; 77.1 \%$ females); $90 \%$ identified as White, $8.6 \%$ as Asian or Asian British, and $1.4 \%$ selected 'Other'; $85.7 \%$ were native English speakers and none required hearing aids. Participants were primarily recruited via an online research participation platform, from an existing pool of Psychology undergraduate students from a UK-based university, whose data on the personality traits of interest had already been collected as part of an ongoing collaborative project co-coordinated by the current study's authors. Other students and non-students aged 18 and above, who had also completed these personality measures, were recruited via word of mouth.

Musicians, pregnant women, antidepressants and/or sleep tranquilizer users, and those with musicogenic epilepsy and/or severe hearing loss were excluded from the study. Participants were asked to indicate if they had any current medical condition (e.g. ADHD/ADD, anxiety, cardiac arrhythmias, epilepsy, depression) and whether they were on medication. This information was collected to minimize the potential adverse effects of induced stress on well-being, although no changes to the procedure were deemed necessary based on this information. All participants received either a $£ 5$ payment or 50 course credits. This study was approved by the Faculty of Engineering and Physical Sciences Research Ethics Committee.

\section{Materials}

\section{Arithmetic Stimuli}

Participants completed several arithmetic verification tasks. The stimuli were presented as white numbers on a black background and consisted of a simple addition of two- and/or three-digit numbers, followed by its sum (e.g. " $37+147=184 ", " 462+211=568 ")$. Arithmetic tasks were presented in four blocks (tasks 1-4) comprising 44 arithmetic stimuli each, with an even number of correct and incorrect responses, and a set of instructions at the start of each block (see Instructions for Arithmetic Tasks in Online Resource 1). Stimuli were presented in a randomized order. Participants were asked to click right on a computer mouse if the answer to the sum were incorrect and left if it were correct, as quickly and accurately as possible. Each stimulus was presented for $10 \mathrm{~s}$, being replaced by the following one if no response was provided.

\section{Stress Manipulation}

The stress induction was an adapted paradigm from Doumas et al. (2018), involving the completion of arithmetic tasks alongside an increasing number of stressors. While task 1 involved the arithmetic stimuli only, time pressure was introduced in task 2. Participants were informed that a white line indicating other participants' average calculation time would be presented and that a green progress bar would run across the bottom of the screen, turning red once it passed the white line (see Fig. 1). In reality, this line was set in reference to $70 \%$ of each participant's response time in task 1 . Between tasks 2 and 3, the social evaluative threat (SET) was initiated. The main researcher excused themselves from the room to retrieve the second researcher. On their return, both researchers fictitiously discussed the participant's performance and then informed them they were underperforming and had to try harder (see SET Script in Online Resource 1). The participant then completed task 3 under time pressure, whilst observed by both researchers. Subsequently, in this version of the paradigm, a waiting period was introduced, during which participants waited for information on whether their performance had been sufficiently quick and accurate for progression to task 4 . Participants were made to believe that underperformance on these parameters would result in early termination of the experiment, though task performance was not actually assessed during the waiting period, nor did it influence task progression. Task 4 consisted of arithmetic tasks with no added time pressure.

\section{Music Stimuli}

According to pre-established selection criteria, a hip-hop/rap playlist and a relaxing playlist, constituted by 10 songs each, were curated in collaboration with a music producer and a research assistant with musicology expertise (see Music Selection Criteria and Tables S4-S6 in Online Resource 1). All songs were trimmed to last two minutes, enabling sufficient time for appreciation of its content whilst sustaining participants' interest. In total, music exposure lasted for $20 \mathrm{~min}$, which is within a duration range commonly used in literature (Krout, 2007; Nilsson, 2008). All songs were faded in and out appropriately, to provide smoother transitions and assist relaxation (Krout, 2007). The order in which the songs were presented was randomized for all participants. All of the songs selected were either originally non-explicit or edited by a music producer to mute any explicit language, to abide by 
a

b

$462+211=568$

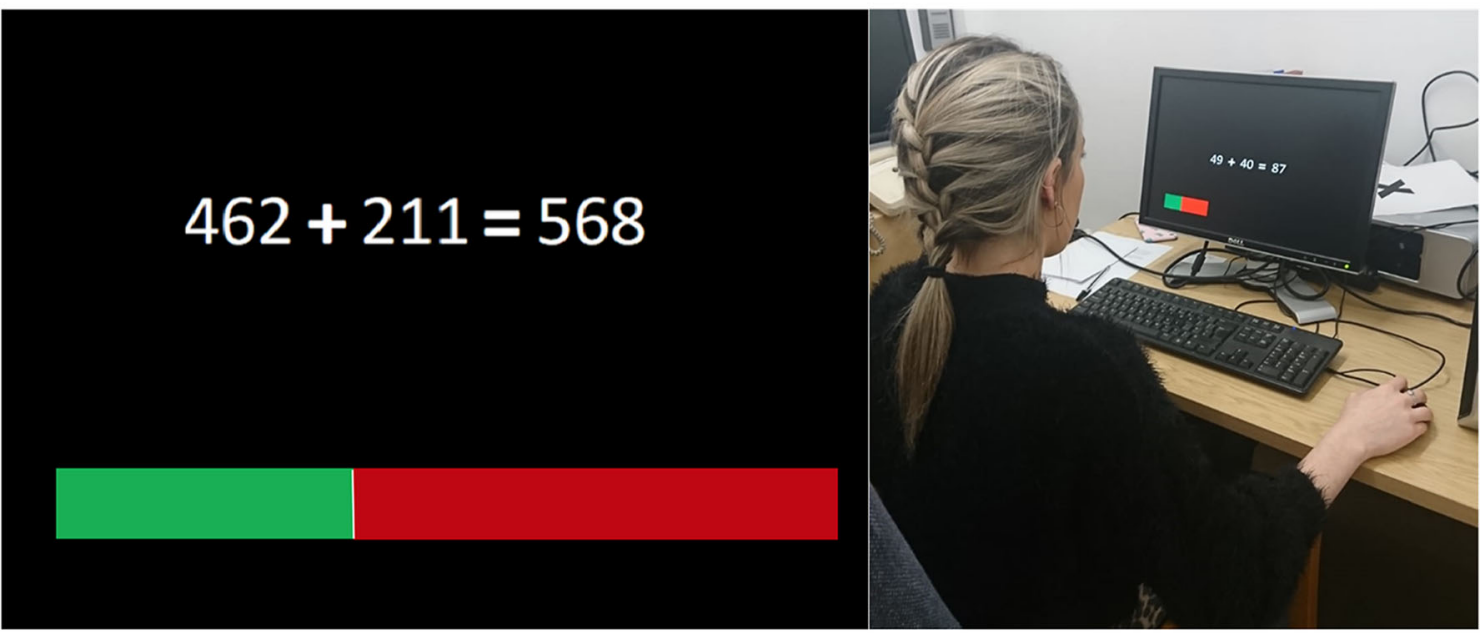

C

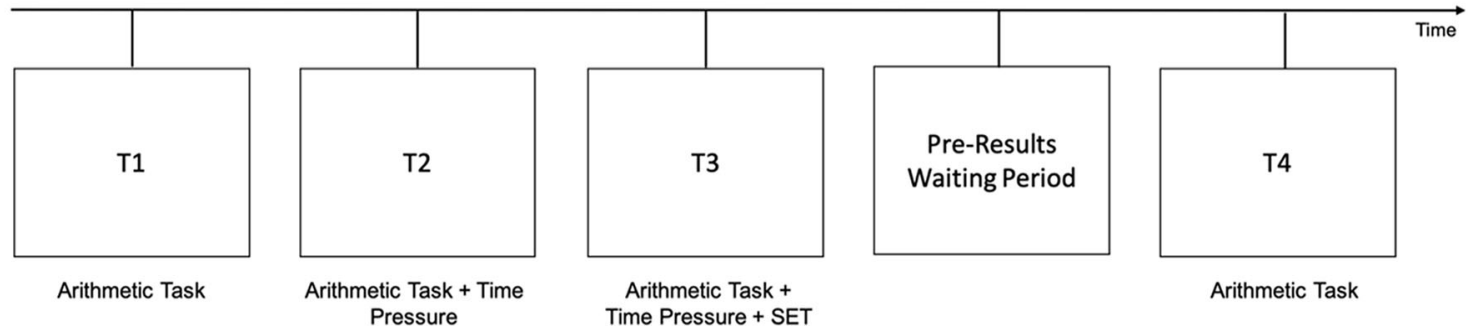

Fig. 1 Experimental Setup. Note. The experimental setup includes (a) screen display for tasks 2 and 3, (b) overall setup for completion of Task 2, and (c) experimental timeline

offensive language regulations in UK broadcast content (Ofcom, 2019). This ensured individuals were not exposed to any impactful explicit language beyond their day-to-day experiences. To more objectively assess and, where possible, quantify each parameter of selection criteria for both playlists, several approaches and tools were employed. An in-depth criteria formulation process was followed to enable a genrewide and feature-specific generalization of findings, beyond the stimuli itself.

\section{Measures}

The Short Dark Triad questionnaire (SD3; Jones \& Paulhus, 2014), with 27 items in total, was used to assess the DT traits, containing 9 items for each trait: narcissism (e.g. "People see me as a natural leader."), psychopathy (e.g. "I like to get revenge on authorities."), and Machiavellianism (e.g. "It's not wise to tell your secrets".). Each item was rated on a 5-point Likert scale ( $1=$ strongly disagree, $5=$ strongly agree). To obtain overall trait scores, responses on each subscale were averaged, after effectuating required item reversals. Given that previous studies found no direct relationship between Machiavellianism and stress nor performance under stress, the main traits of interest were narcissism and psychopathy.
The 'Stress' subscale of the Depression, Anxiety and Stress Scale (DASS21; Lovibond \& Lovibond, 1995) was used to determine participants' state-stress. The subscale is constituted by a total of 7 items (e.g. "I found it hard to wind down") which participants rated using a 4-point Likert scale $(0=$ did not apply to me at all, $3=$ applied to me very much or most of the time), in relation to their experiences of stress over the week before completing this measure. The overall stress score was calculated by multiplying the sum of scores on each item by 2 .

The Short Test of Music Preferences Revised, STOMP-R (Rentfrow \& Gosling, 2003, revised 2009), a 23-item scale rated on a 7 -point Likert scale ( $1=$ dislike strongly, $7=$ like strongly), was used to assess music preferences for various music genres (e.g. "Opera", "Gospel”). The genres of interest were 'Rap/hip-hop' and 'Classical'.

An online Qualtrics survey was used to display the STOMP-R and two additional questions: one asking which music genre, from the STOMP-R list, participants were the least likely to select to listen to and the other asking which purposes they usually listened to music for (i.e. "music uses": entertainment, stimulation, relaxation, emotion regulation, or 'other'). Given the scope of the present study, only 'relaxation' and 'emotion regulation' uses were of interest. 


\section{Apparatus and Design}

The dependent variables were self-reported stress levels, task calculation time, and task accuracy. Participants verbally indicated how stressed they felt on a 10-point Likert scale $(1=$ not stressed at all, 10 $=$ extremely stressed) as a measurement of stress. Accuracy was recorded as the percentage of correct responses, and calculation time was recorded from the correct responses, as the average time taken to respond to these questions. The independent variables were music condition, time, narcissism, psychopathy, and Machiavellianism, although 'Machiavellianism' was added for exploratory analyses only. The music condition, a between-participant variable, had three levels: 'no music' (i.e. control), 'relaxing music', and 'hiphop/rap'. To reflect how commonly classical music is perceived and researched as one of the most relaxing music styles, the terms "classical music" and "relaxing music" were used interchangeably throughout this study. Time, a withinparticipant variable, had six levels: 'after task 1', 'after task 2', 'after task 3', 'during waiting period', 'after waiting period', and 'after task 4'. As some of the DT traits tend not to yield particularly high scores in the general population (Ullrich et al., 2008) these between-participant variables were dichotomized ('high'/'low') according to population norms based on a sample of 387 undergraduate students (Jones \& Paulhus, 2014). Analyses of co-variance (ANCOVA) were used to assess the variation in stress and performance over time (i.e. accuracy, calculation time) in function of music group and personality trait scores. Hierarchical multiple regression analyses were used to assess the moderating effect of music uses, classical music preference, and hip-hop/rap music preference on the relationships between music and stress, personality and stress, and personality and performance. State-stress was included as a covariate on all main analyses to control for individual differences in the emotional state of stress. Data on the least likely genre participants would select to listen to was also collected.

The arithmetic tasks were performed on a desktop PC using E-Prime (version 2.0), through which accuracy and calculation time were recorded. Music stimuli were presented via a MacBook Pro laptop running Apple Music software, connected to a set of professional over-the-ear, noise-canceling, stereo headphones (Sennheiser HD202 ii).

\section{Procedure}

The SD3 and DASS21 questionnaires were completed before the experimental procedure. Individuals signed up to participate in the study either via an online research participation platform or direct communication with the main researcher. Those interested in participating were sent a briefing sheet and an information form via email, being asked to complete and return the form to the researcher. Participants were then selected based on the information provided, according to pre-established criteria. The selected participants were asked to attend an individual face-to-face experimental session at a UK-based university lab, at a date/time of their choosing. Participants were evenly and randomly allocated to one of three music groups ('no music', 'relaxing music', 'hip-hop/ rap music'), using Excel functionalities. Only the main experimenter was aware of the participants' allocated group during the experimental session. The participants were initially informed that this study was investigating the relationship between music and cognitive performance, and were presented with evidence suggesting this relationship. Accordingly, participants were not aware of the true nature of the investigation; that the test was devised to induce stress.

The experimental session was conducted by two experimenters, who were introduced to each participant at arrival. Participants sat by a desk and were given an information sheet and consent form to sign. After obtaining informed consent, the second experimenter left the room and participants completed the online Qualtrics survey on a pre-set computer. They were then informed they would be completing 4 sets of arithmetic tasks, preceded by a practice trial, and instructed to carefully read and follow all information given before each set of tasks. It was emphasized they should respond as accurately and quickly as possible throughout, as performance quality, measured as 'speed' and 'accuracy', would determine their progression to task 4. Participants then confirmed these instructions were clear and were given the opportunity to ask questions. The experimental tasks were then initiated (see Fig. 1).

Firstly, participants completed a practice trial, followed by tasks 1 and 2. While participants read the instructions for task 3 , the main experimenter excused themselves from the room to retrieve the second experimenter and the SET was introduced. After the completion of task 3, the waiting period was initiated. Participants were reminded that their performance results would determine whether they would progress to the following phase. Participants were then handed a pair of headphones and asked to attend to the stimuli presented through them. It was emphasized that they should focus only on what would be presented through the headphones, even if no sound was being played at times, and they should, therefore, try their best to ignore any distractions (e.g. mobile phones). The computer screen, which displayed the instructions for task 4 , was turned off in front of each participant and it was explained that this was an additional measure to ensure they did not divert their attention from the auditory stimuli. During the waiting period, the 'no music' group was exposed to silence, whilst the 'hip-hop/rap' and 'relaxing music' groups listened to hiphop/rap and classical music, respectively. This waiting period lasted for $20 \mathrm{~min}$, albeit participants were not made aware of its duration. Participants were left alone during this time, except for when the main researcher came in to record their 
stress levels (as explained below), leaving straight after. At the end of the waiting period, participants were informed they had progressed to the following phase and were asked to complete task 4.

Self-reported stress levels were recorded after tasks 1, 2, 3, and 4, as well as 10 min into the waiting period and immediately after it (i.e. after $20 \mathrm{~min}$ of music/silence exposure). At the end of the experiment, each participant was asked to rate their maximum stress levels during the experiment and indicate at what timepoint they experienced it (i.e. after task 1, after task 2 , after task 3 , during waiting period, after waiting period, after task 4). All participants were then fully debriefed. The overall duration of the experiment was 40-50 min.

\section{Results}

Stress was measured at six different timepoints, with higher scores indicating higher levels of stress. To account for initial variations in stress, stress levels reported after task 1 were established as baseline values and subtracted from the stress levels measured in the subsequent timepoints, before data analyses. Five timepoints were then included in the analyses: after task 2 ('T2'), after task 3 ('T3'), after the first 10 min of the waiting period ('WP1'), at the end of the waiting period ('WP2'), and after task 4 ('T4'). All four timepoints at which accuracy and calculation time were recorded (i.e. tasks 1-4) were included in the analyses.

\section{Efficacy of Stress Induction}

A repeated-measures analysis of variance (ANOVA) was conducted to assess the impact of the stress-inducing paradigm on participants' stress levels over time (see Fig. 2). Using a Greenhouse-Geisser correction, results showed a main effect of time on stress levels, $F(2.07,142.70)=153.15, p<.001, \eta_{\mathrm{p}}^{2}$ $=.69$. Post hoc pairwise comparisons using the Bonferroni test determined that participants were significantly more stressed at T3, in comparison to T2 $(p<.001,95 \%$ CI $[0.42,1.24])$,
WP1 $(p<.001,95 \%$ CI [3.27, 4.85]), WP2 $(p<.001,95 \%$ CI $[3.70,5.44])$, and T4 $(p<.001,95 \%$ CI $[2.84,4.22])$ (see Table 1 for descriptive statistics). The stress levels reported at T2 were significantly higher than WP1 $(p<.001,95 \% \mathrm{CI}$ $[2.46,4.00])$, WP2 $(p<.001,95 \%$ CI $[2.89,4.59])$, and T4 $(p<.001,95 \%$ CI $[2.02,3.38])$. The stress levels reported at WP2 were significantly lower than both WP1 $(p=.003,95 \%$ CI $[-0.91,-0.12])$ and T4 $(p<.001,95 \%$ CI $[-1.57,-0.52])$. There were no significant differences between stress levels reported at WP1 and T4. Additionally, $80 \%$ of the participants reported $\mathrm{T} 3$ as the most stressful timepoint throughout the experiment, whereas $14.3 \%$ were the most stressed at T2, $4.3 \%$ at $\mathrm{T} 1$, and $1.4 \%$ at WP1.

\section{Accuracy and Calculation Time}

Variations in accuracy and calculation time over time were examined (see Fig. 3). A repeated-measures ANOVA, using the Huynh-Feldt correction, showed a main effect of time on accuracy, $F(2.44,168.11)=22.68, p<.001, \eta_{p}^{2}=.25$. Post hoc pairwise comparisons using the Bonferroni test determined that accuracy was significantly higher at T4, in comparison to $\mathrm{T} 1(p<.001,95 \%$ CI $[7.60,14.61]), \mathrm{T} 2(p<.001$, $95 \%$ CI $[2.37,10.62])$, and T3 ( $p<.001,95 \%$ CI $[4.20,9.24])$. Accuracy at T3 was significantly higher than T1 $(p=.002$, $95 \%$ CI $[1.24,7.53])$. There were no further significant differences.

A repeated-measures ANOVA, using the Huynh-Feldt correction, showed a main effect of time on calculation time, $F(2.79,192.39)=81.04, p<.001, \eta_{\mathrm{p}}^{2}=.54$. Post hoc pairwise comparisons using the Bonferroni test showed that calculation time was significantly higher at $\mathrm{T} 1$, in comparison to T2 $(p<.001,95 \%$ CI [732.35, $1250.17])$, T3 ( $p<.001,95 \%$ CI [1031.59, 1598.39]), and T4 $(p<.001,95 \%$ CI $[850.36,1317.82])$. Calculation time at T3 was significantly lower than T2 $(p=.001,95 \% \mathrm{CI}$ $[-537.93,-109.52])$ and T4 $(p=.048,95 \%$ CI $[-460.28$, $-1.52])$. There were no differences between calculation time recorded at $\mathrm{T} 2$ and $\mathrm{T} 4$.

Table 1 Summary of Descriptive Statistics for Stress Levels Reported at Each Measurement Timepoint per Music Group

\begin{tabular}{lllll}
\hline Time of Stress Measurement & $\begin{array}{l}\text { Relaxing } \\
\mathrm{N}=24) \\
M(S D)\end{array}$ & $\begin{array}{l}\text { Hip-Hop/Rap } \\
(N=23)\end{array}$ & $\begin{array}{l}\text { Control } \\
(\mathrm{N}=23) \\
M(S D)\end{array}$ & $\begin{array}{l}\text { Pooled Music Groups } \\
(N=47) \\
M(S D)\end{array}$ \\
\hline T2 & $1.5(1.7)$ & $1.3(1.3)$ & $1.3(1.7)$ & $1.4(1.5)$ \\
$M(S D)$
\end{tabular}

Maximum/minimum stress levels $= \pm 9$ 


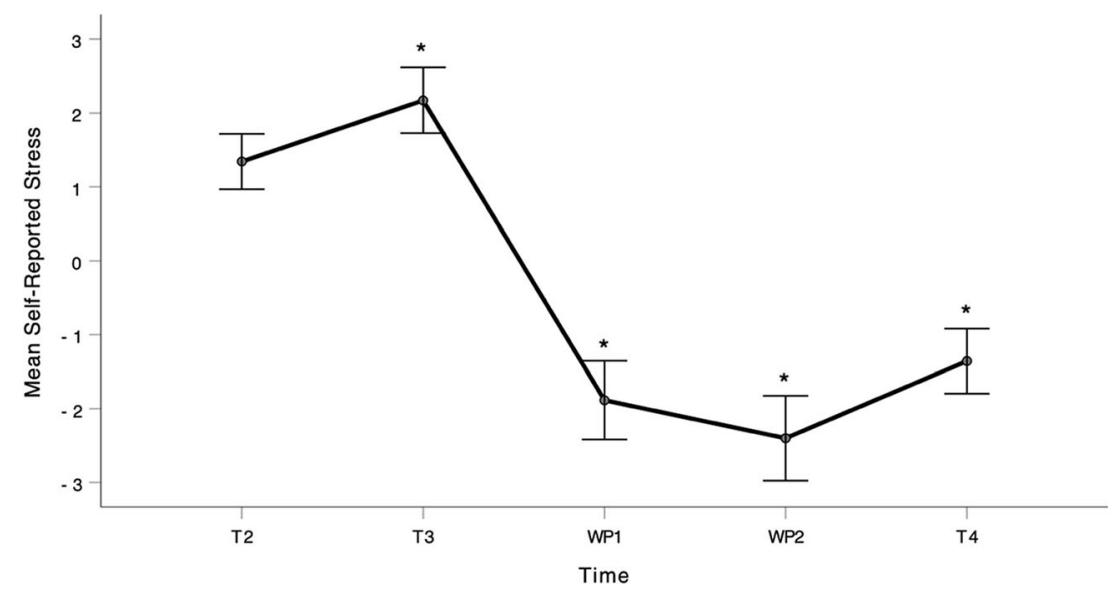

Fig. 2 Changes in Mean Self-Reported Stress Over Time. Note. The timepoints were coded as follows: $\mathrm{T} 2=$ after task $2, \mathrm{~T} 3=$ after task 3 , $\mathrm{WP} 1=$ after the first $10 \mathrm{~min}$ of the waiting period, $\mathrm{WP} 2=$ at the end of the waiting period, $\mathrm{T} 4=$ after task 4 . 'Mean self-reported stress' values correspond to mean stress levels after the subtraction of baseline levels (maximum $/$ minimum $= \pm 9$ ); the error bars represent $95 \%$ confidence intervals. The asterisks represent $p<.01$ compared to the previous timepoint
Fig. 3 Changes in (a) Mean Calculation Time and (b) Accuracy Over Time. Note. The timepoints were coded as follows: $\mathrm{T} 1=\operatorname{task} 1, \mathrm{~T} 2=\operatorname{task} 2, \mathrm{~T} 3=$ task $3, \mathrm{~T} 4=$ task 4 . The error bars represent $95 \%$ confidence intervals; the asterisks represent $p<.05$ compared to the previous timepoint

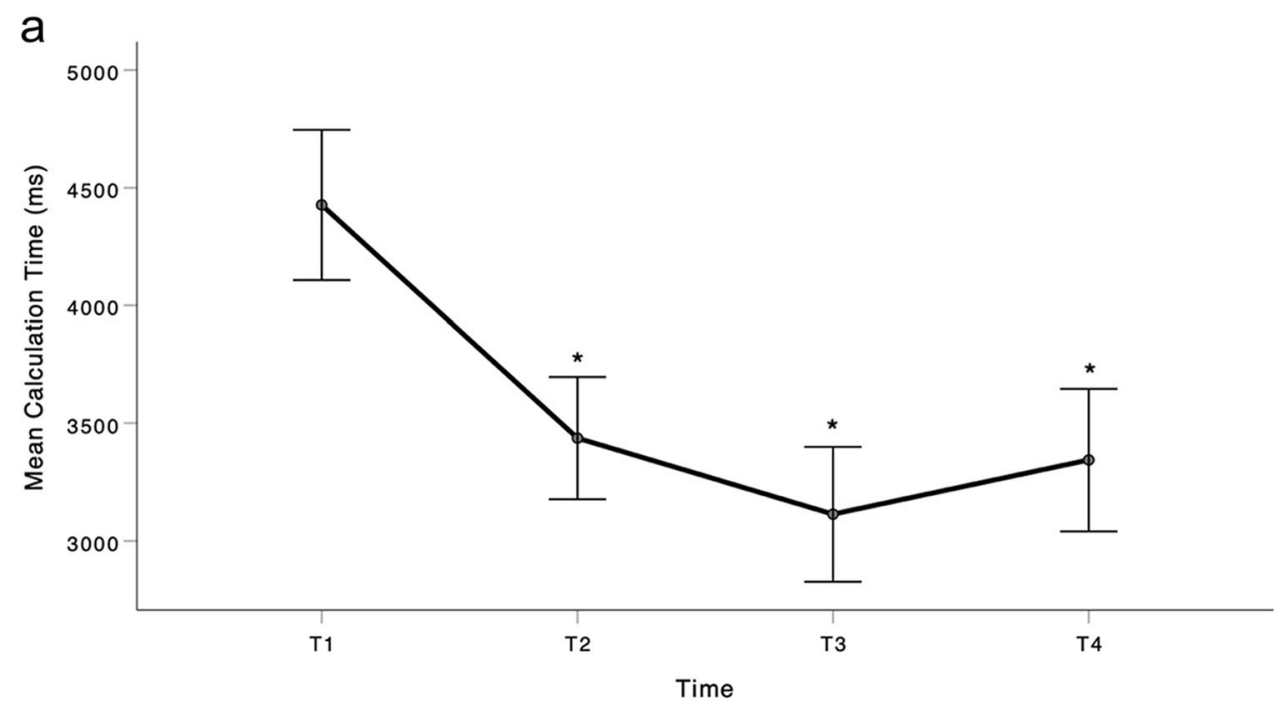

b

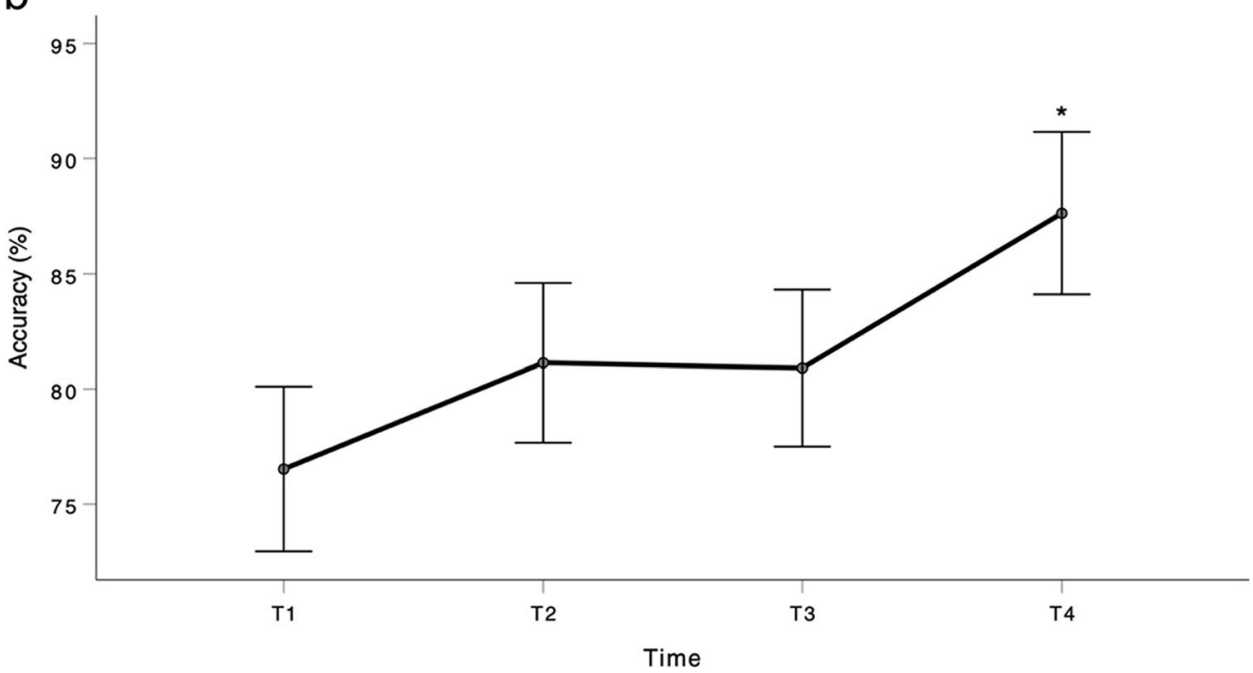




\section{Music Listening \& Stress}

No significant differences in baseline stress levels were found between the hip-hop/rap, relaxing, and control groups. Thus, this variable was not added as a covariate in the analyses. Descriptive statistics for stress levels over time, per group, are displayed in Table 1.

A two-way $3 \times 5$ mixed ANCOVA was conducted to examine the effects of music group (relaxing, hip-hop/rap, no music) and time (T2, T3, WP1, WP2, T4) on self-reported stress, with state-stress added as a covariate. The ANCOVA, with a Greenhouse-Geisser correction, showed there was a time by group interaction on stress levels, $F(4.32,142.55)=$ $3.24, p=.012, \eta_{\mathrm{p}}^{2}=.09$ ), indicating the influence of group on stress may be dependent on the measurement timepoint. There was also a main effect of group on stress levels, $F(2,66)=$ $3.72, p=.030, \eta_{\mathrm{p}}^{2}=.10$, with the music groups displaying lower stress levels than controls, on average (see Table 1 for descriptive statistics). Post hoc pairwise comparisons using the Bonferroni test showed no significant differences in stress levels between the different groups.

Given the auditory stimuli placement, music group allocation was only expected to influence stress after T3. Though music exposure could have impacted stress levels reported at T4, several other factors not measured in this study (e.g. relief after task progression, increased task familiarity) could have also prompted variations in stress. Hence, it would be overly speculative to assess the stress-reducing effect of music through stress levels recorded at T4. Considering this, to adequately further inspect the influence of music group on stress, two one-way ANCOVAs were conducted separately for stress levels reported at WP1 and WP2, with state-stress added as a covariate.

The first one-way ANCOVA indicated that there was a significant main effect of group on stress levels reported at $\mathrm{WP} 1, F(2,66)=3.80, p=.027, \eta_{\mathrm{p}}^{2}=.10$. Post hoc pairwise comparisons using the Bonferroni test showed no significant differences in stress levels between groups. At WP2, the ANCOVA showed a significant main effect of group on stress levels, $F(2,66)=5.81, p=.005, \eta_{\mathrm{p}}^{2}=.15$ (see Fig. 4). Post hoc pairwise comparisons using the Bonferroni test determined that controls were significantly more stressed than participants in the relaxing ( $p=.008, d=1.02,95 \% \mathrm{CI}[0.45,3.75])$ and hip-hop/rap group ( $p=.029, d=0.77,95 \% \mathrm{CI}[0.14,3.46])$ at WP2 (see Table 1 for descriptive statistics). There were no significant differences in stress levels between participants in the relaxing and hip-hop/rap groups.

As the relaxing and hip-hop/rap groups displayed similar stress levels after music exposure, these were pooled as an overall 'music' group. A two-way $2 \times 5$ mixed ANCOVA was conducted to examine the effects of music exposure (music, no music) and time (T2, T3, WP1, WP2, T4) on stress. State-stress was included as a covariate. No significant differences in baseline stress levels were found between the groups, so this variable was not added as a covariate. The ANCOVA, with a Greenhouse-Geisser correction, showed that there was a time by music exposure interaction on stress levels, $F(2.16$, $144.95)=6.34, p=.002, \eta_{\mathrm{p}}^{2}=.09$. There was also a main effect of music exposure on stress, $F(1,67)=7.54, p=.008$, $\eta_{\mathrm{p}}^{2}=.10$ (see Fig. 5).

Independent samples t-tests indicated that stress levels in the groups exposed to music were significantly lower than those reported by controls at WP1 $(t(68)=2.8, p=.007, d=$ $0.73,95 \%$ CI $[0.43,2.59])$, WP2 $(t(68)=3.43, p=.001, d=$ $0.89,95 \% \mathrm{CI}[0.82,3.09])$, and T4 $(t(68)=3.45, p=.001, d=$ $0.91,95 \%$ CI $[0.63,2.37])$.

\section{Personality, Stress \& Performance}

Due to the number of tests ran when examining the associations between the DT and stress, calculation time, and
Fig. 4 Mean Stress Levels Reported at the End of the Waiting Period (WP2) per Music Group. Note. 'Mean self-reported stress' values correspond to mean stress levels after the subtraction of baseline levels (maximum/ minimum $= \pm 9$ ); the error bars represent $95 \%$ confidence intervals; the asterisk represents $p<.01$ compared to the previous group

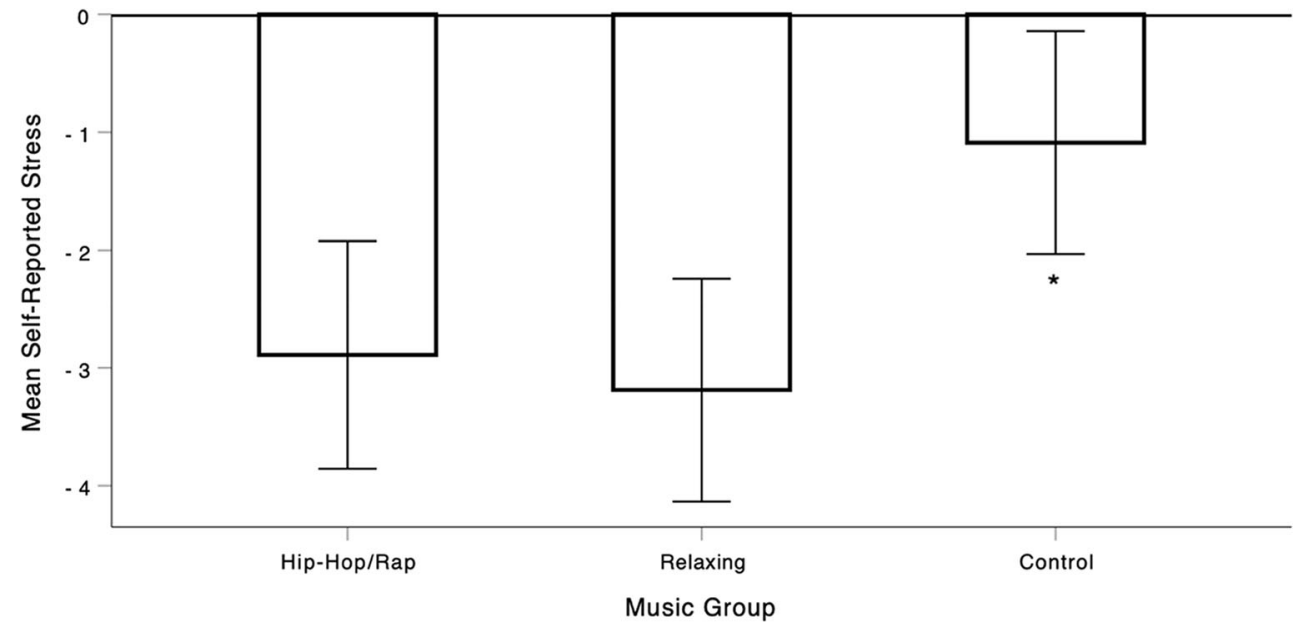


Fig. 5 Changes in Mean SelfReported Stress Over Time for the Music and No Music Exposure Groups Note. The timepoints were coded as follows: $\mathrm{T} 2=$ after task $2, \mathrm{~T} 3=$ after task $3, \mathrm{WP} 1=$ after the first $10 \mathrm{~min}$ of the waiting period, $\mathrm{WP} 2=$ at the end of the waiting period, $\mathrm{T} 4=$ after task 4; 'mean self-reported stress' values correspond to mean stress levels after the subtraction of baseline levels (maximum/minimum $= \pm 9$ ); the error bars represent $95 \%$ confidence intervals

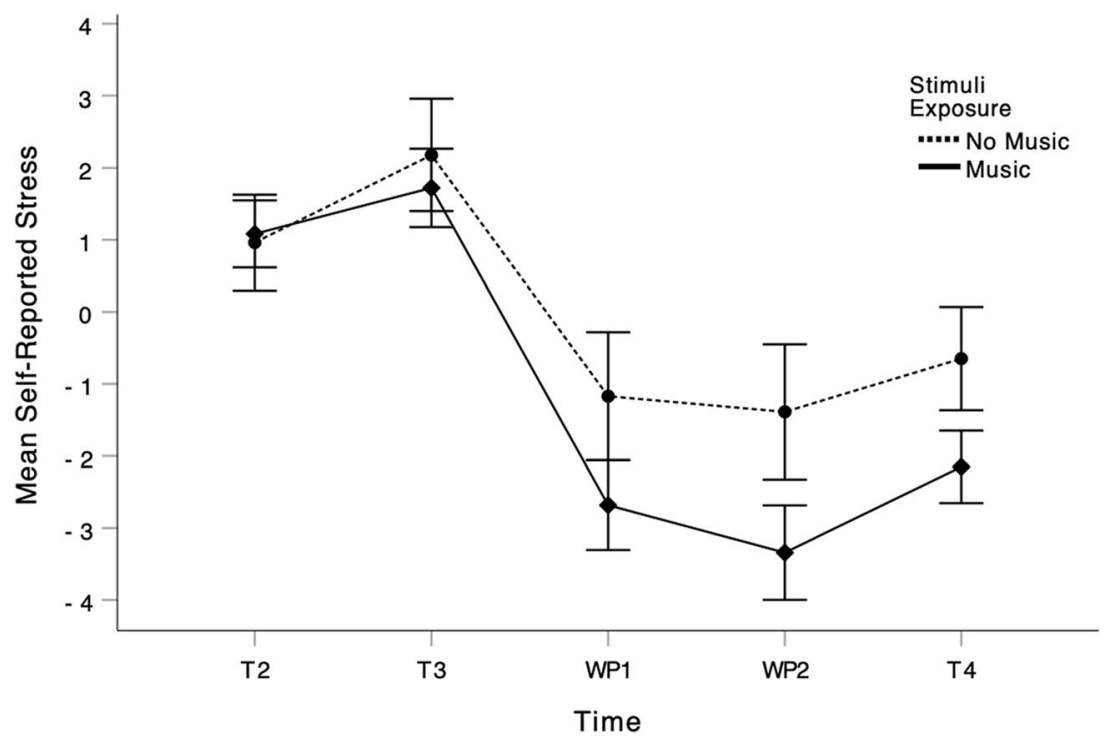

accuracy, the increased risk of Type I errors was accounted for and the $p$ value adjusted using the Bonferroni procedure (Olejnik et al., 1997). The statistical significance was determined as $p<.017$ for outcomes concerning the direct effect(s) of personality on stress and performance. Descriptive statistics and reliability coefficients for the DT trait measures are displayed in Table 2. Descriptive statistics for stress levels, accuracy, and calculation time for each timepoint, per level of each DT trait, are displayed in Table 3.

A series of $2 \times 5$ and $2 \times 4$ mixed ANCOVAs were conducted to assess the influence of psychopathy, narcissism and Machiavellianism scores (high, low), separately, on stress levels over time (T2, T3, WP1, WP2, T4), accuracy, and calculation time in each task (T1, T2, T3, T4). State-stress was added as a covariate. No significant associations were found. Given the discrepancies in group size derived from the dichotomization of trait scores, these were entered as continuous covariates in a series of three ANCOVAs to further examine their association with stress and performance. There were no significant effects.

\section{Music Preferences \& Uses as Moderators}

To test the hypotheses that music uses and music preferences moderate the relationship between (1) music and stress, (2) personality and stress, and (3) personality and performance, a series of hierarchical multiple regression analyses were conducted. All focal continuous predictor and moderator variables were centered to minimize multicollinearity issues (Aiken et al., 1991). Each separate analysis examined only one outcome variable, one predictor and one moderator at a time, with state-stress added as a covariate. Only preferences for classical music and hip-hop/rap were included in the analyses in representation of "music preferences". As no participants indicated classical music nor hip-hop/rap as their least likely genre to select to listen to, this data was not further examined. Descriptive statistics for classical music and hiphop rap preferences and frequencies for each music uses category are displayed in Table 4.

\section{Music, Personality, \& Stress}

A series of separate regression models showed that music preferences and uses did not moderate the association between music group nor music exposure and stress over time.

Regarding the interactions between personality, music preferences and music uses, stress levels over time were added as outcome variables; psychopathy, narcissism, and Machiavellianism as predictors; and classical music preference, hip-hop/rap preference, and music uses as moderators into multiple separate regression models.

The moderating effect of classical music preference on the association between narcissism and stress levels at WP2 was

Table 2 Summary of Descriptive Statistics and Reliability Coefficients for the DT Trait Measures

\begin{tabular}{llllll}
\hline Measure & $M(S D)$ & Skewness & Kurtosis & McDonald's $\omega$ & Cronbach's $\alpha$ \\
\hline Psychopathy & $2.0(0.6)$ & 0.6 & 0.3 & 0.83 & 0.74 \\
Narcissism & $2.6(0.6)$ & 0.2 & -0.1 & 0.77 & 0.69 \\
Machiavellianism & $3.1(0.5)$ & 0.4 & 1.5 & 0.69 & 0.58 \\
\hline
\end{tabular}


Table 3 Summary of Descriptive Statistics for Stress Levels, Calculation Time and Accuracy Recorded at Each Measurement Timepoint per Level of Psychopathy, Narcissism and Machiavellianism

\begin{tabular}{|c|c|c|c|c|c|c|}
\hline Variables & $\begin{array}{l}\text { Low } \\
\text { Psychopathy } \\
(N=53) \\
M(S D)\end{array}$ & $\begin{array}{l}\text { High } \\
\text { Psychopathy } \\
(N=17) \\
M(S D)\end{array}$ & $\begin{array}{l}\text { Low } \\
\text { Narcissism } \\
(N=46) \\
M(S D)\end{array}$ & $\begin{array}{l}\text { High } \\
\text { Narcissism } \\
(N=24) \\
M(S D)\end{array}$ & $\begin{array}{l}\text { Low } \\
\text { Machiavellianism } \\
(N=33) \\
M(S D)\end{array}$ & $\begin{array}{l}\text { High } \\
\text { Machiavellianism } \\
(N=37) \\
M(S D)\end{array}$ \\
\hline \multicolumn{7}{|l|}{ Stress } \\
\hline After task 2 & $1.2(1.6)$ & $1.8(1.3)$ & $1.3(1.5)$ & $1.5(1.8)$ & $1.2(1.6)$ & $1.5(1.6)$ \\
\hline After task 3 & $2.0(1.9)$ & $2.8(1.7)$ & $1.9(1.7)$ & $2.6(2.0)$ & $2.0(1.6)$ & $2.3(2.0)$ \\
\hline $\begin{array}{l}10 \text { min into waiting } \\
\text { period }\end{array}$ & $-2.0(2.3)$ & $-1.5(2.0)$ & $-2.0(2.4)$ & $-1.7(2.0)$ & $-2.2(2.4)$ & $-1.6(2.1)$ \\
\hline End of waiting period & $-2.6(2.5)$ & $-1.9(2.0)$ & $-2.5(2.4)$ & $-2.3(2.4)$ & $-2.9(2.3)$ & $-2.0(2.4)$ \\
\hline After task 4 & $-1.5(1.9)$ & $-0.9(1.4)$ & $-1.4(1.8)$ & $-1.3(2.0)$ & $-1.6(1.7)$ & $-1.2(1.9)$ \\
\hline \multicolumn{7}{|l|}{ Calculation Time (ms) } \\
\hline Task 1 & $4532.9(1343.4)$ & $4098.0(1317.1)$ & $\begin{array}{l}4526.3 \\
\quad(1319.5)\end{array}$ & $4237.4(1389.0)$ & $4727.4(1301.1)$ & $4159.6(1335.8)$ \\
\hline Task 2 & $3527.3(1092.2)$ & $3151.3(1072.8)$ & $\begin{array}{l}3496.6 \\
\quad(1084.6)\end{array}$ & 3319.8 (1119.7) & $3769.5(1160.8)$ & $3138.5(945.7)$ \\
\hline Task 3 & $3262.6(1211.9)$ & $2643.7(1066.6)$ & $\begin{array}{l}3178.9 \\
\quad(1152.5)\end{array}$ & $2984.6(1304.5)$ & $3358.0(1229.4)$ & $2893.1(1147.2)$ \\
\hline Task 4 & 3499.5 (1173.0) & $2855.6(1460.3)$ & $\begin{array}{l}3397.6 \\
\quad(1154.4)\end{array}$ & $3238.8(1483.8)$ & $3647.5(1232.3)$ & $3071.8(1254.2)$ \\
\hline \multicolumn{7}{|l|}{ Accuracy (\%) } \\
\hline Task 1 & $76.1(15.4)$ & $77.9(14.1)$ & $75.5(15.7)$ & $78.5(13.7)$ & 74.7 (13.9) & $78.2(16.0)$ \\
\hline Task 2 & $80.6(15.4)$ & $82.9(11.8)$ & $82.1(12.7)$ & $79.3(17.7)$ & $81.8(12.8)$ & $80.5(16.1)$ \\
\hline Task 3 & $81.0(13.2)$ & $80.5(17.7)$ & $81.1(13.8)$ & $80.6(15.4)$ & $79.3(14.3)$ & $82.4(14.3)$ \\
\hline Task 4 & $88.1(13.1)$ & $86.1(19.5)$ & $88.4(13.8)$ & $86.1(16.7)$ & $87.3(14.9)$ & $88.0(14.9)$ \\
\hline
\end{tabular}

Maximum $/$ minimum stress levels $= \pm 9$

examined. In the first step of the regression analysis, narcissism and classical music preference were entered as predictors and neither had a significant direct effect on stress. In the second step, the interaction between narcissism and classical music preference was added, and it explained a significant proportion of the variance in stress levels reported at the end of the waiting period, $\Delta R^{2}=.09, \Delta F(1,65)=4.69, p=.03$, $95 \%$ CI $[-1.31,-0.05], b=-0.68, t(65)=-2.17, p<.05$. The interaction plot (see Fig. 6) indicates that when participants reported a low preference for classical music, those who scored high on narcissism displayed higher stress levels.

Table 4 Summary of Descriptive Statistics for Classical and Hip-Hop Rap Music Preferences and Frequencies for Each Category of Music Uses

\begin{tabular}{lllll}
\hline Variable & $M$ & $S D$ & $N$ & $\%$ \\
\hline Classical Music Preference & 3.9 & 2.0 & - & - \\
Hip-Hop/Rap Preference & 5.3 & 1.6 & - & - \\
Music Uses Category & & & & \\
$\quad$ Neither Relaxation nor Emotion Regulation & - & - & 14 & 20 \\
Relaxation & - & - & 27 & 38.6 \\
Emotion Regulation & - & - & 5 & 7.1 \\
Relaxation and Emotion Regulation & - & - & 24 & 34.3 \\
Total & - & - & 70 & 100 \\
\hline
\end{tabular}

When average levels of classical music preference were reported, high and low narcissism scorers displayed similar stress levels. At high levels of classical music preference, high narcissism scorers displayed lower stress levels. Music preferences and uses did not moderate any further associations between personality and stress.

\section{Personality and Performance}

Accuracy and calculation time recorded at T1, T2, T3, and T4 were entered as outcome variables; psychopathy, narcissism, and Machiavellianism were entered as predictors; and classical music preference, hip-hop/rap preference, and music uses were entered as moderators into several separate regression models.

The moderating effect of music uses on the relationship between narcissism scores and calculation time in task 1 was examined. In the first step of the regression analysis, narcissism and music uses were entered as predictors and neither had a significant direct effect on calculation time. In the second step, the interactions between narcissism and the different levels of music uses were added. The interaction term between narcissism and 'relaxation vs neither relaxation nor emotion regulation' significantly predicted changes in calculation time recorded in task 1 , 
Fig. 6 Interaction Plot Representing the Associations Between Self-Reported Stress (at the End of the Waiting Period) and Narcissism at Different Levels of Classical Music Preference. Note. The maximum and minimum stress levels were $\pm 9$

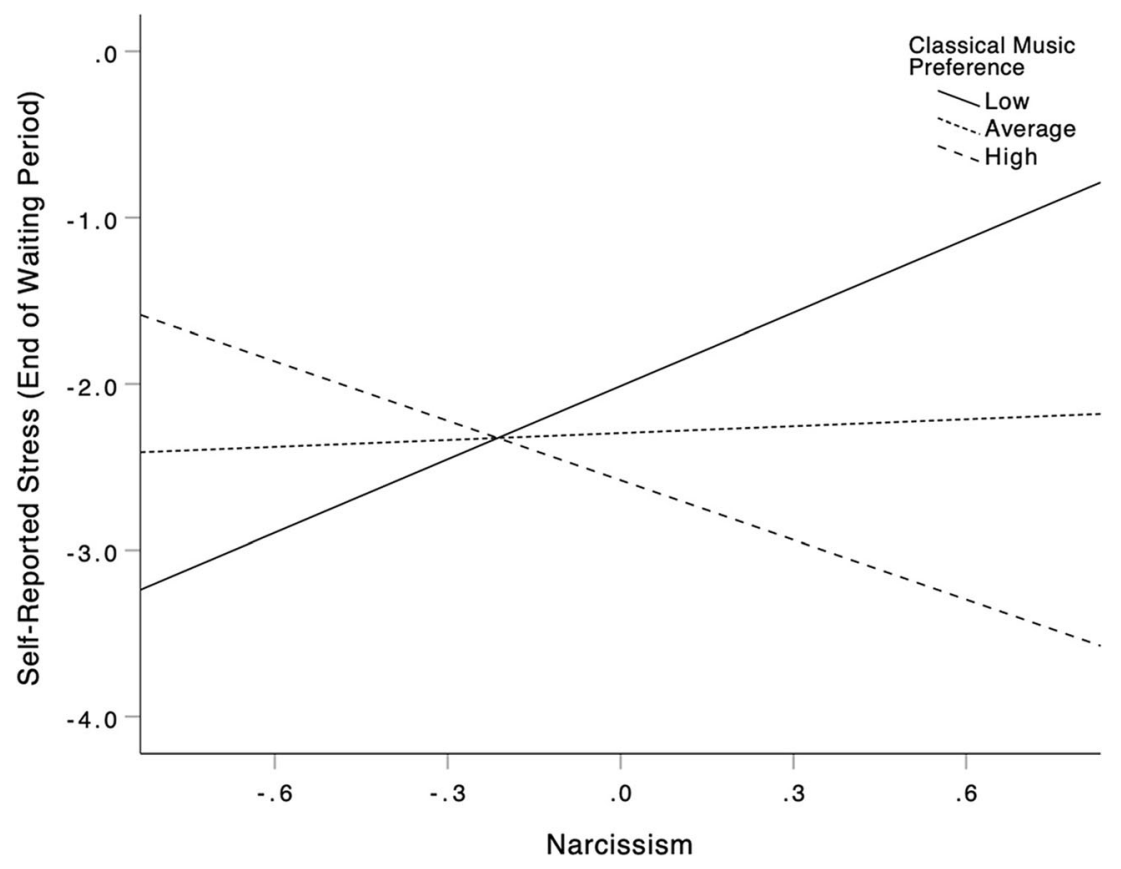

$b=1062.72, t(61)=2.14, p=.036, p<.05$. The simple slopes analysis indicated that when participants reported not to use music for relaxation nor emotion regulation, narcissism scores predicted a decrease in calculation time by 769.5 milliseconds, $b=-769.50, t(61)=2.20, p=.031$, $95 \%$ CI [-1467.73, -71.27], $p<.05$ (see Fig. 7). Lower calculation time was an indicator of enhanced performance in our sample (see correlation analysis below). When participants reported to use music for relaxation, emotion regulation, or both, narcissism did not predict variations in calculation time. Music preferences and uses did not moderate any further associations between personality and accuracy nor calculation time.

To contextualize these outcomes, three variables representing the overall mean value across timepoints for calculation time, stress, and accuracy were computed. A correlation analysis using these variables was then conducted. Results showed a small significant negative association between calculation time and stress, $r(68)=-.28$, $p=.02$, and a moderate positive correlation between calculation time and accuracy, $r(68)=.32, p=.007$ (see Table 5).
Fig. 7 Interaction Plot Representing the Associations Between Calculation Time in Task 1 (in Milliseconds) and Narcissism at the Different Categorical Levels of Music Uses

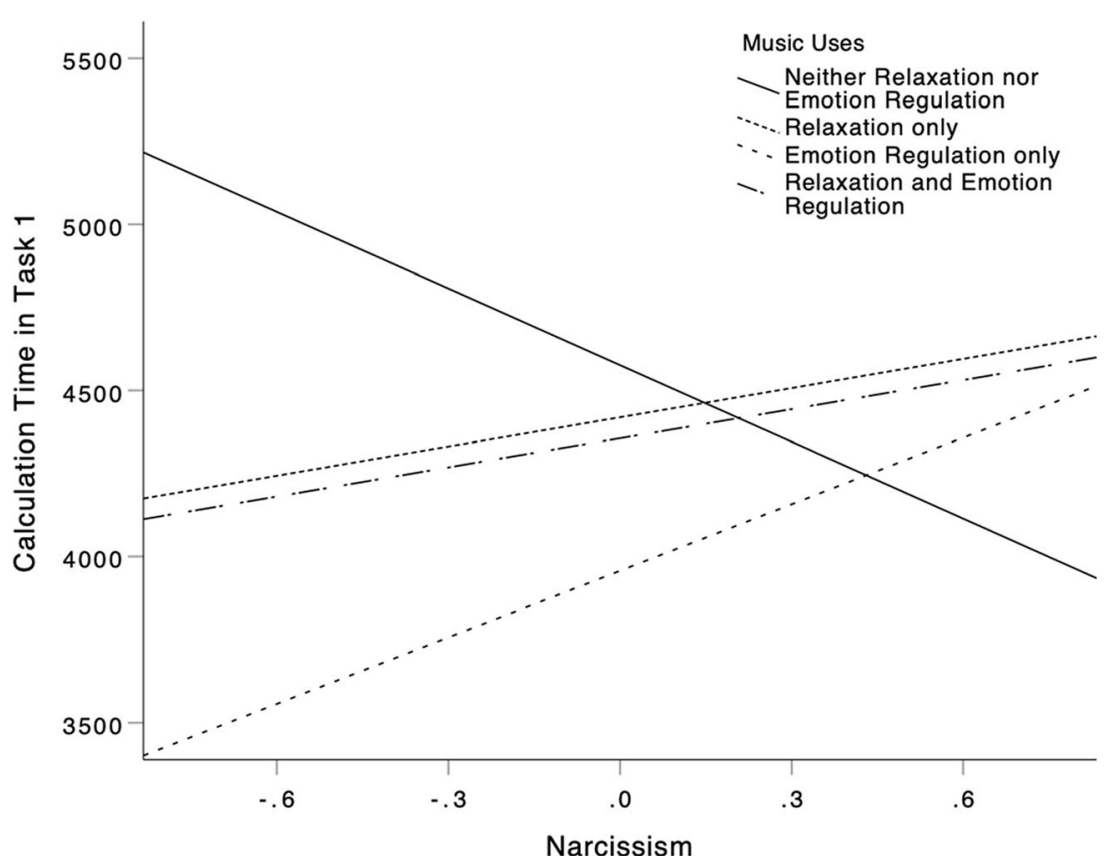


Table 5 Correlations Between Calculation Time, Stress and Accuracy

\begin{tabular}{llllll}
\hline Variable & $M$ & $S D$ & 1 & 2 & 3 \\
\hline
\end{tabular}

1. Overall Calculation Time (ms) $3579.7 \quad 1136.4 \quad$

2. Overall Stress

$\begin{array}{lllll}-0.4 & 1.6 & -.28 * & -\end{array}$

3. Overall Accuracy (\%)

$81.6 \quad 12.9 \quad-.32 * *-.05-$

$\mathrm{N}=70 ;$ maximum $/$ minimum stress levels $= \pm 9$

${ }^{*} p<0.05$. $* * p<0.01$

\section{Discussion}

This study investigated the effects of music listening and personality on stress, and of personality on performance, as well as the moderating effects of music preferences and uses on these relationships. As hypothesized, both music groups were significantly less stressed than controls after $20 \mathrm{~min}$ of music/silence exposure. Results showed that classical music and hip-hop/rap equally facilitated stress reduction, challenging the discrepant recognition of classical music as relaxing, compared to hip-hop/ rap, and strengthening the scant evidence linking hip-hop/rap to laboratory-induced stress. Supporting a second hypothesis, narcissism predicted indirectly variation in stress and performance. Narcissists who preferred classical music manifested better stress regulation than those with average and low classical music preference. Additionally, moderation and correlation analyses showed that narcissists who did not regularly use music for relaxation nor emotion regulation displayed enhanced performance, but also greater stress. This confirms the predicted moderation effect of music preferences and uses of music on the associations between narcissism, stress, and performance. Perhaps the most interesting finding of this study indicated that narcissism can benefit individuals' stress responses or cognitive performance, depending on variations in music preferences and music uses. Going beyond widespread negative connotations, these findings expand on available protective factors and approaches that help regulate everyday stress and optimize performance under stress.

\section{Music and Stress}

Substantiating the current findings, classical music has been consistently evidenced to reduce laboratory-induced stress (Burns et al., 2002; Chafin et al., 2004; Labbé et al., 2007). Contrastingly, few studies have examined the effects of hiphop/rap on induced stress, with little research, if any, exploring these using the current study design and stimuli placement. The stress-reducing effect of hip-hop/rap corroborates previous findings, in which this genre elicited lower stress than silence during task completion (Satchel, 2015). This effect may stem from its structural features which resemble those evidenced to prompt relaxation (e.g. repetitive/ rhythmic; lower end of tempo range) (Elliott et al., 2011;
Moradipanah et al., 2009; Neumann, 2000; Uhlig et al., 2018). These outcomes highlight a need to re-evaluate overpopularized conceptualizations of 'relaxing' music likely founded on connotations established outside the music and stress domain (e.g. undesirability of behaviors associated with hip-hop/rap), but that appear to influence the focus of research conducted within it (Gomes Arrulo, n.d.-a).

Consistent with a previous study, the relaxing effect of music was independent of preference (Bernardi et al., 2006). Music uses did not influence the stress-reducing effect of music either, though this was incongruent with previous literature (Chin \& Rickard, 2014; Saarikallio et al., 2013). The discrepant sample size in each 'music uses' category and the lack of a well-established measure of music uses may explain these unanticipated outcomes. Albeit unsupportive of our hypotheses, these results strengthen the observed stress-reducing effect of hip-hop/rap by implying that its relaxing nature manifests itself regardless of genre preferences and habitual music uses.

\section{Personality, Stress, and Performance}

The present outcomes suggest narcissists can selectively adjust their music practices to regulate stress or optimize performance. Despite the pioneering nature of these findings, the observed interactions between narcissism, classical music preference, and music uses corroborate research highlighting the importance of assessing the combined influence of personality and music variables on emotional outcomes (Helsing, 2012; Juslin et al., 2008).

Infrequent music engagement may imply an underdeveloped stress regulation ability (Chin \& Rickard, 2014), consequently heightening negative stress responses. Additionally, according to the Inverted-U theory, performance is enhanced by stress increments until moderate stress levels are reached (i.e. optimal stress) (Kavanagh, 2005). Hence, narcissists with little music engagement habits, not impeded by the enhanced stress regulation their counterparts experience, may reach optimal stress levels, consequently displaying improved performance. Contrastingly, potentially having greater stress regulation abilities through music engagement, narcissists who prefer classical music may display low rather than optimal stress levels, showing no performance improvement.

Congruent with previous studies (McInerney, 2018; Papageorgiou et al., c), though contradicting our hypothesis, narcissism did not directly predict stress nor performance. Contrasting predictions and previous findings, neither did psychopathy (Hansen et al., 2007; McInerney, 2018; Noser et al., 2014). This may be attributed to using the SD3 scale as a measurement tool, as it biasedly quantifies the grandiose dimension of narcissism (Maples et al., 2014) and the impulsivity facet of psychopathy (Jones \& Paulhus, 2014). Regarding psychopathy, specifically, the unanticipated findings may be 
due to trait scores being asymmetrically distributed and below the population mean (Jones \& Paulhus, 2014). Consistent with previous research, no associations were found between Machiavellianism and stress (Kajonius \& Björkman, 2018; Noser et al., 2014) nor cognitive performance (McInerney, 2018).

\section{Limitations}

This study had several limitations. Firstly, no physiological measures of stress were included, though incorporating these could have compromised the study's deceptive nature. Despite introducing ecologically valid stressors and deception to prevent unnatural responses, using a daily diary approach could have increased ecological validity. Also, although the effects of state-stress were controlled for, measuring variables directly associated with anxiety derived from arithmetic (e.g. mathematics anxiety) could have further informed the present findings, given that an arithmetic stressor was used. Moreover, focusing on silence for 20 min may have been aversive for controls. Without a less unpleasant, active control eliciting levels of arousal, attentional and affective involvement comparable to music listening, stress reduction may not be confidently regarded as a product of music itself (Chanda \& Levitin, 2013). Nonetheless, previous studies have found silence and certain genres to similarly increase relaxation (Labbé et al., 2007; Malakoutikhah et al., 2020), diminishing the likelihood of music functioning merely as less aversive stimuli and strengthening the reliability of findings involving non-active controls. Additionally, as the dimensions of psychopathy and narcissism were not differentiated, the findings can only be extended to these traits as measured by the SD3 scale. The generalizability of the findings is also limited to arithmetic stressors with elements of social evaluation and time pressure. As such, future research could benefit from exploring the different dimensions of narcissism (e.g. vulnerable, grandiose) and replicating the present findings using different sources of stress. Lastly, considering music preferences' stability and developmental nature (BonnevilleRoussy et al., 2013; Rentfrow \& Gosling, 2003), adjustments to preferences may imply ill-defined, unquantifiable processes. Assessing the effects of music listening frequency alongside preferences could have enabled more quantifiable behavioral recommendations for narcissists.

\section{Conclusions}

The present study has found that hip-hop/rap can reduce stress and that narcissism can either benefit stress responses or cognitive performance, depending on one's music preferences and habitual music uses. By searching 'beneath the surface' of well-established negative connotations, this study challenges the dichotomized categorization of music genres and personality traits, paving the way for a more inclusive approach to the identification and use of influential factors in stress reduction and performance under stress. Future studies may acknowledge the multifaceted nature of hip-hop/rap and narcissism for an integrated understanding of their contribution to the well-being of non-clinical populations.

Supplementary Information The online version contains supplementary material available at https://doi.org/10.1007/s12144-021-01664-0.

Acknowledgements We thank Belle Edelman, Jonathan Clarke and the InteRRaCt Lab for assisting with data collection, music curation, and participant recruitment.

Data, Materials and/or Code Availability The datasets generated during and/or analysed during the current study, data analyses files, and supplemental materials are available in the OSF repository [https://osf.io/ xcfb9/?view_only=30cc441264dd46bfb68a4f881239b355].

Authors' Contributions All authors contributed to the development of the study concept. T. Gomes Arrulo developed the study design. T. Gomes Arrulo and K.A. Papageorgiou contributed to participant recruitment and data collection. T. Gomes Arrulo led the curation of music resources and M. Doumas provided the arithmetic stimuli for the experimental procedure. Testing, data analyses and interpretation was performed by $\mathrm{T}$. Gomes Arrulo under the supervision of K.A. Papageorgiou and M. Doumas. T. Gomes Arrulo drafted the manuscript, and K.A. Papageorgiou and M. Doumas provided critical revisions. All authors approved the final version of the manuscript for submission.

Funding This work was supported by a Department for the Economy (DfE) $\mathrm{PhD}$ Studentship awarded to Teresa Gomes Arrulo. The funding source had no direct involvement in the conduct of the research nor preparation of the article.

\section{Declarations}

Ethics Approval All procedures performed involving human participants were in accordance with the ethical standards of the institutional research committee and with the 1964 Helsinki Declaration and its later amendments or comparable ethical standards. The study was approved by the Faculty of Engineering and Physical Sciences Research Ethics Committee at Queen's University Belfast.

Consent to Participate Informed consent was obtained from all individual participants included in the study.

Consent for Publication The authors affirm that human research participants provided informed consent for publication of the images in Fig. 1 b.

Conflicts of Interest/Competing Interests On behalf of all authors, the corresponding author states that there is no conflict of interest.

Open Access This article is licensed under a Creative Commons Attribution 4.0 International License, which permits use, sharing, adaptation, distribution and reproduction in any medium or format, as long as you give appropriate credit to the original author(s) and the source, provide a link to the Creative Commons licence, and indicate if changes were 
made. The images or other third party material in this article are included in the article's Creative Commons licence, unless indicated otherwise in a credit line to the material. If material is not included in the article's Creative Commons licence and your intended use is not permitted by statutory regulation or exceeds the permitted use, you will need to obtain permission directly from the copyright holder. To view a copy of this licence, visit http://creativecommons.org/licenses/by/4.0/.

\section{References}

Gomes Arrulo, T. (n.d.-a). Genre discrepancies and methodological rigour in music and stress research: a systematic review. Manuscript in preparation.

Gomes Arrulo, T. (n.d.-b). The Dark Triad and stress in non-clinical samples: a systematic review. Manuscript in preparation.

Aiken, L. S., West, S. G., \& Reno, R. R. (1991). Multiple regression: Testing and interpreting interactions. Sage.

Bernardi, L., Porta, C., \& Sleight, P. (2006). Cardiovascular, cerebrovascular, and respiratory changes induced by different types of music in musicians and non-musicians: The importance of silence. Heart, 92(4), 445-452. https://doi.org/10.1136/hrt.2005.064600.

Bonneville-Roussy, A., Rentfrow, P. J., Xu, M. K., \& Potter, J. (2013). Music through the ages: Trends in musical engagement and preferences from adolescence through middle adulthood. Journal of Personality and Social Psychology, 105(4), 703-717. https://doi. org/10.1037/a0033770

Burns, J. L., Labbé, E., Arke, B., Capeless, K., Cooksey, B., Steadman, A., \& Gonzales, C. (2002). The effects of different types of music on perceived and physiological measures of stress. Journal of Music Therapy, 39(2), 101-116. https://doi.org/10.1093/jmt/39.2.101.

Chafin, S., Roy, M., Gerin, W., \& Christenfeld, N. (2004). Music can facilitate blood pressure recovery from stress. British Journal of Health Psychology, 9(3), 393-403. https://doi.org/10.1348/ 1359107041557020.

Chamorro-Premuzic, T., Swami, V., Furnham, A., \& Maakip, I. (2009). The big five personality traits and uses of music: A replication in Malaysia using structural equation modeling. Journal of Individual Differences, 30(1), 20-27. https://doi. org/10.1027/1614-0001.30.1.20.

Chanda, M. L., \& Levitin, D. J. (2013). The neurochemistry of music. Trends in Cognitive Sciences, 17(4), 179-193. https://doi.org/10. 1016/j.tics.2013.02.007.

Chin, T., \& Rickard, N. S. (2014). Emotion regulation strategy mediates both positive and negative relationships between music uses and well-being. Psychology of Music, 42(5), 692-713. https://doi.org/ 10.1177/0305735613489916.

Coleman, S. R., Pincus, A. L., \& Smyth, J. M. (2019). Narcissism and stress-reactivity: A biobehavioural health perspective. Health Psychology Review, 13(1), 35-72. https://doi.org/10.1080/ 17437199.2018.1547118.

Doumas, M., Morsanyi, K., \& Young, W. R. (2018). Cognitively and socially induced stress affects postural control. Experimental Brain Research, 236(1), 305-314. https://doi.org/10.1016/j.humov.2015. 01.015 .

Elliott, D., Polman, R., \& McGregor, R. (2011). Relaxing music for anxiety control. Journal of Music Therapy, 48(3), 264-288. https://doi.org/10.1093/jmt/48.3.264.

Fatima, S., \& Shahid, Z. (2020). Conditional indirect relations between executive functions, emotion regulation, and Machiavellianism in young men and women. Personality and Individual Differences, 165, 110140. https://doi.org/10.1016/j.paid.2020.110140.

Faul, F., Erdfelder, E., Lang, A.-G., \& Buchner, A. (2007). G*power 3: A flexible statistical power analysis program for the social, behavioral, and biomedical sciences. Behavior Research Methods, 39, 175-191. https://doi.org/10.3758/BF03193146.
Fink, G. (Ed.). (2010). Integrative aspects of stress response. Stress science: neuroendocrinology (pp. 323-426). Academic Press.

Finn, S., \& Fancourt, D. (2018). The biological impact of listening to music in clinical and nonclinical settings: A systematic review. Progress in Brain Research, 173-200. https://doi.org/10.1016/bs. pbr.2018.03.007.

Greenberg, D. M., Rentfrow, P. J., \& Baron-Cohen, S. (2015). Can music increase empathy? Interpreting musical experience through the empathizing-systemizing (ES) theory: Implications for autism. Empirical Musicology Review, 10(1-2), 80-95. https://doi.org/10. 18061/emr.v10i1-2.4603.

Halko, M. L., \& Kaustia, M. (2015). Risk ON/risk OFF: Risk-taking varies with subjectively preferred and disliked music. PLoS One, 10(8), e0135436. https://doi.org/10.1371/journal.pone.0135436.

Hansen, A. L., Johnsen, B. H., Thornton, D., Waage, L., \& Thayer, J. F. (2007). Facets of psychopathy, heart rate variability and cognitive function. Journal of Personality Disorders, 21(5), 568-582. https:// doi.org/10.1521/pedi.2007.21.5.568.

Hare, R. D. (1984). Performance of psychopaths on cognitive tasks related to frontal lobe function. Journal of Abnormal Psychology, 93(2), 133-140. https://doi.org/10.1037/0021-843X.93.2.133.

Hart, S. D., Forth, A. E., \& Hare, R. D. (1990). Performance of criminal psychopaths on selected neuropsychological tests. Journal of Abnormal Psychology, 99(4), 374-379. https://doi.org/10.1037/ 0021-843X.99.4.374.

Hart, W., Adams, J. M., \& Tortoriello, G. (2017). Narcissistic responses to provocation: An examination of the rage and threatened-egotism accounts. Personality and Individual Differences, 106, 152-156. https://doi.org/10.1016/j.paid.2016.10.049.

Helsing, M. (2012). Everyday music listening: The importance of individual and situational factors for musical emotions and stress reduction. Department of Psychology; Psykologiska institutionen.

Jiang, J., Zhou, L., Rickson, D., \& Jiang, C. (2013). The effects of sedative and stimulative music on stress reduction depend on music preference. The Arts in Psychotherapy, 40(2), 201-205. https://doi. org/10.1016/j.aip.2013.02.002.

Jiang, J., Rickson, D., \& Jiang, C. (2016). The mechanism of music for reducing psychological stress: Music preference as a mediator. The Arts in Psychotherapy, 48, 62-68. https://doi.org/10.1016/j.aip. 2016.02.002.

Jonason, P. K., Koehn, M. A., Bulyk, R. A., \& Davis, M. D. (2020). Standing out and not fitting in: The dark triad traits and social values. The Journal of Social Psychology, 160(2), 164-169. https://doi.org/ $10.1080 / 00224545.2019 .1623162$.

Jones, D. N., \& Figueredo, A. J. (2013). The core of darkness: Uncovering the heart of the dark triad. European Journal of Personality, 27(6), 521-531. https://doi.org/10.1002/per.1893.

Jones, D. N., \& Paulhus, D. L. (2014). Introducing the short dark triad (SD3) a brief measure of dark personality traits. Assessment, 21(1), 28-41. https://doi.org/10.1177/1073191113514105.

Juslin, P. N., Liljeström, S., Västfjäll, D., Barradas, G., \& Silva, A. (2008). An experience sampling study of emotional reactions to music: Listener, music, and situation. Emotion, 8(5), 668-683. https://doi.org/10.1037/a0013505.

Kajonius, P, J., \& Björkman, T. (2018). Dark malevolent traits and everyday perceived stress. Current Psychology, 1-6. https://doi.org/10. 1007/s12144-018-9948-x.

Kavanagh, J. (2005). Stress and performance a review of the literature and its applicability to the military. Rand Corp Santa Monica CA.

Kemper, K. J., \& Danhauer, S. C. (2005). Music as therapy. Southern Medical Journal, 98(3), 282-288.

Kirkland, K., \& King, S, H. (2019). Rap \& Recovery: A music therapy process-oriented intervention for adults with concurrent disorders. Approaches: An Interdisciplinary Journal of Music Therapy, 11(1).

Krout, R. E. (2007). Music listening to facilitate relaxation and promote wellness: Integrated aspects of our neurophysiological responses to 
music. The Arts in Psychotherapy, 34(2), 134-141. https://doi.org/ 10.1016/j.aip.2006.11.001.

Labbé, E., Schmidt, N., Babin, J., \& Pharr, M. (2007). Coping with stress: The effectiveness of different types of music. Applied Psychophysiology and Biofeedback, 32(3-4), 163-168. https://doi. org/10.1007/s10484-007-9043-9.

Lin, Y., Mutz, J., Clough, P. J., \& Papageorgiou, K. A. (2017). Mental toughness and individual differences in learning, educational and work performance, psychological well-being, and personality: A systematic review. Frontiers in Psychology, 8, 1345. https://doi. org/10.3389/fpsyg.2017.01345.

Lovibond, P. F., \& Lovibond, S. H. (1995). The structure of negative emotional states: Comparison of the depression anxiety stress scales (DASS) with the Beck depression and anxiety inventories. Behaviour Research and Therapy, 33(3), 335-343.

Lozon, J., \& Bensimon, M. (2014). Music misuse: A review of the personal and collective roles of "problem music". Aggression and Violent Behavior, 19(3), 207-218. https://doi.org/10.1016/j.avb. 2014.04.003.

Malakoutikhah, A., Dehghan, M., Ghonchehpoorc, A., Afshar, P, P., \& Honarmand, A. (2020). The effect of different genres of music and silence on relaxation and Anxiety: A Randomized Controlled Trial. EXPLORE. https://doi.org/10.1016/j.explore.2020.02.005.

Maples, J. L., Lamkin, J., \& Miller, J. D. (2014). A test of two brief measures of the dark triad: The dirty dozen and short dark triad. Psychological Assessment, 26(1), 326-331. https://doi.org/10. 1037/a0035084.

McInerney, A. M. K. (2018). Under pressure: The role of mental toughness and dark triad traits in performance under stress.

Moradipanah, F., Mohammadi, E., \& Mohammadil, A. Z. (2009). Effect of music on anxiety, stress, and depression levels in patients undergoing coronary angiography. EMHJ-Eastern Mediterranean Health Journal, 15(3), 639-647.

Neumann, F. (2000). Hip hop: Origins, characteristics and creative processes. The World of Music, 51-63.

Nilsson, U. (2008). The anxiety-and pain-reducing effects of music interventions: A systematic review. AORN Journal, 87(4), 780-807. https://doi.org/10.1016/j.aorn.2007.09.013.

Noser, A. E., Zeigler-Hill, V., \& Besser, A. (2014). Stress and affective experiences: The importance of dark personality features. Journal of Research in Personality, 53, 158-164. https://doi.org/10.1016/j.jrp. 2014.10.007.

Ofcom. (2019). Ofcom broadcast and on demand bulletin. Issue number 387. Ofcom. https://www.ofcom.org.uk/ data/assets/pdf file/ 0022/167701/Issue-387-broadcast-and-on-demand-bulletin.pdf

Olejnik, S., Li, J., Supattathum, S., \& Huberty, C. J. (1997). Multiple testing and statistical power with modified Bonferroni procedures. Journal of Educational and Behavioral Statistics, 22(4), 389-406. https://doi.org/10.3102/10769986022004389.

Papageorgiou, K. A., Wong, B., \& Clough, P. J. (2017). Beyond good and evil: Exploring the mediating role of mental toughness on the dark triad of personality traits. Personality and Individual Differences, 119, 19-23. https://doi.org/10.1016/j.paid.2017.06. 031.

Papageorgiou, K. A., Malanchini, M., Denovan, A., Clough, P. J., Shakeshaft, N., Schofield, K., \& Kovas, Y. (2018). Longitudinal associations between narcissism, mental toughness and school achievement. Personality and Individual Differences, 131, 105110. https://doi.org/10.1016/j.paid.2018.04.024.

Papageorgiou, K. A., Benini, E., Bilello, D., Gianniou, F. M., Clough, P. J., \& Costantini, G. (2019a). Bridging the gap: A network approach to dark triad, mental toughness, the big five, and perceived stress.
Journal of Personality, 87(6), 1250-1263. https://doi.org/10.1111/ jopy. 12472.

Papageorgiou, K. A., Denovan, A., \& Dagnall, N. (2019b). The positive effect of narcissism on depressive symptoms through mental toughness: Narcissism may be a dark trait but it does help with seeing the world less grey. European Psychiatry, 55, 74-79. https://doi.org/10. 1016/j.eurpsy.2018.10.002.

Papageorgiou, K. A., Gianniou, F. M., Wilson, P., Moneta, G. B., Bilello, D., \& Clough, P. J. (2019c). The bright side of dark: Exploring the positive effect of narcissism on perceived stress through mental toughness. Personality and Individual Differences, 139, 116-124. https://doi.org/10.1016/j.paid.2018.11.004.

Paulhus, D. L., \& Williams, K. M. (2002). The dark triad of personality: Narcissism, Machiavellianism, and psychopathy. Journal of Research in Personality, 36(6), 556-563. https://doi.org/10.1016/ S0092-6566(02)00505-6.

Rentfrow, P. J., \& Gosling, S. D. (2003). The do re mi's of everyday life: The structure and personality correlates of music preferences. Journal of Personality and Social Psychology, 84(6), 1236-1256. https://doi.org/10.1037/0022-3514.84.6.1236.

Saarikallio, S. H. (2008). Music in mood regulation: Initial scale development. Musicae Scientiae, 12(2), 291-309. https://doi.org/10. 1177/102986490801200206.

Saarikallio, S., Nieminen, S., \& Brattico, E. (2013). Affective reactions to musical stimuli reflect emotional use of music in everyday life. Musicae Scientiae, 17(1), 27-39. https://doi.org/10.1177/ 1029864912462381

Sadeh, N., \& Verona, E. (2008). Psychopathic personality traits associated with abnormal selective attention and impaired cognitive control. Neuropsychology, 22(5), 669-680. https://doi.org/10.1037/ a0012692.

Satchel, K, M. (2015). A closer look at the interaction between music, personality and its' effect on individuals' stress. Unpublished Manuscript. Downloaded from commons.emich.edu, Eastern Michigan University.

Uhlig, S., Jansen, E., \& Scherder, E. (2018). "Being a bully isn't very cool...": Rap \& Sing Music Therapy for enhanced emotional selfregulation in an adolescent school setting-a randomized controlled trial. Psychology of Music, 46(4), 568-587. https://doi.org/10.1177/ 0305735617719154.

Ullrich, S., Farrington, D. P., \& Coid, J. W. (2008). Psychopathic personality traits and life-success. Personality and Individual Differences, 44(5), 1162-1171. https://doi.org/10.1016/j.paid. 2007.11.008.

Wallace, H. M., \& Baumeister, R. F. (2002). The performance of narcissists rises and falls with perceived opportunity for glory. Journal of Personality and Social Psychology, 82(5), 819-834. https://doi.org/ 10.1037/0022-3514.82.5.819.

Wendt, G. W., \& Bartoli, A. J. (2019). Understanding the psychopathystress association in typical developing adults: The role of emotional deficits. Personality and Individual Differences, 149, 296-301. https://doi.org/10.1016/j.paid.2019.06.016.

Yehuda, N. (2011). Music and stress. Journal of Adult Development, 18(2), 85-94. https://doi.org/10.1007/s10804-010-9117-4.

Zeigler-Hill, V., Clark, C. B., \& Pickard, J. D. (2008). Narcissistic subtypes and contingent self-esteem: Do all narcissists base their selfesteem on the same domains? Journal of Personality, 76(4), 753774. https://doi.org/10.1111/j.1467-6494.2008.00503.x.

Publisher's Note Springer Nature remains neutral with regard to jurisdictional claims in published maps and institutional affiliations. 